\title{
Research on Stray Current Distribution in a Multitrain Subway System using Finite Element Modeling
}

\author{
Shan Lin ${ }^{1}$, Xuehua Liu' ${ }^{2}$ Xianwei Zhang ${ }^{2}$, Zhichao Cai ${ }^{2, *}$ \\ ${ }^{1}$ Guangzhou Metro Design\&Research Institute Co.,Ltd, Guangzhou 510010, China. \\ ${ }^{2}$ School of Electrical and Automation Engineering, East China Jiaotong University, Nanchang 330013, \\ China. \\ "E-mail: czchebut@ foxmail.com
}

Received: 28 June 2021 / Accepted: 30 September 2021 / Published: 10 November 2021

\begin{abstract}
Stray current modeling analysis is an important method to study the leakage and distribution of stray current. To study the stray current distribution law under the combined influence of multiple trains in the up and down subway section, this paper takes the interference of stray current on buried pipelines as the research object and establishes a field-circuit coupling model combining a resistor network model with an electric field model. This paper focuses on the analysis of the distribution of stray current in the soil environment under the condition of multiple trains in up and down section, the change of buried pipeline current and pipe-ground potential under the interference of stray current, the drainage efficiency of a drainage network under different settings, and the protection efficiency of a pipeline anti-corrosion layer against stray current. The simulation results show that the leakage of stray current in the soil is not determined by the number of trains on the line but by the average traction current of the train. The simulation results also show that the drainage effect of the drainage network depends on the longitudinal cross-sectional area of the drainage network. When both the track bed reinforcement and the tunnel structure reinforcement participate in drainage, the efficiency of the drainage network is as high as $81.1 \%$. The protection efficiency of the anti-corrosive layer against stray current is over $90 \%$. The new field-circuit coupling model combines the computational advantages of resistance and the finite element method and provides a new idea for solving the modeling and analysis of stray currents in complex environments.
\end{abstract}

Keywords: stray current, field-circuit coupling, buried pipeline, drainage network, anti-corrosion layer

\section{FULL TEXT}

(C) 2021 The Authors. Published by ESG (www.electrochemsci.org). This article is an open access article distributed under the terms and conditions of the Creative Commons Attribution license (http://creativecommons.org/licenses/by/4.0/). 